\title{
Assessment of hemostatic activation during cardiopulmonary bypass for coronary artery bypass grafting with bivalirudin: Results of a pilot study
}

Andreas Koster, MD, ${ }^{a}$ Ruhi Yeter, MD, ${ }^{\mathrm{b}}$ Semih Buz, MD, ${ }^{\mathrm{b}}$ Hermann Kuppe, MD, ${ }^{\mathrm{a}}$ Roland Hetzer, MD, A. Michael Lincoff, MD, ${ }^{c}$ Cornelius M. Dyke, MD, ${ }^{d}$ Nicholas G. Smedira, MD, ${ }^{e}$ and Bruce Spiess, MD

From the Departments of Anesthesia and Cardiothoracic and Vascular Surgery, ${ }^{\mathrm{b}}$ Deutsches Herzzentrum Berlin, Berlin, Germany; the Department of Cardiovascular Medicine, ${ }^{\mathrm{c}}$ The Cleveland Clinic Foundation, Cleveland, Ohio; the Department of Cardiac Surgery, ${ }^{\mathrm{d}}$ The Sanger Clinic, Gastonia, NC; the Department of Cardiothoracic Surgery, The Cleveland Clinic Foundation, Cleveland, Ohio; and the Department of Cardiothoracic Anesthesia, ${ }^{\mathrm{f}}$ Virginia Commonwealth University, Richmond, Va.

Supported by The Medicines Company (Parsippany, NJ).

Drs Koster, Dyke, and Spiess have a consultancy agreement with The Medicines Company.

Received for publication June 2, 2004; revisions received Sept 2, 2004; accepted for publication Sept 7, 2004.

Address for reprints: Andreas Koster, MD, Deutsches Herzzentrum Berlin, Augustenburger Platz 1, D-13353 Berlin, Germany (E-mail: koster@dhzb.de).

J Thorac Cardiovasc Surg 2005;129:1391-4 $0022-5223 / \$ 30.00$

Copyright $\odot 2005$ by The American Association for Thoracic Surgery

doi:10.1016/j.jtcvs.2004.09.016
Objective: Bivalirudin has been successfully used as a replacement for heparin during on-pump coronary artery bypass grafting. This study was conducted to assess the effects of the currently suggested protocol for bivalirudin on hemostatic activation during cardiopulmonary bypass with and without cardiotomy suction.

Methods: Ten patients scheduled for coronary artery bypass grafting were enrolled. Bivalirudin was given with a bolus of $50 \mathrm{mg}$ in the priming solution and $1.0 \mathrm{mg} / \mathrm{kg}$ for the patient, followed by an infusion of $2.5 \mathrm{mg} \cdot \mathrm{kg}^{-1} \cdot \mathrm{h}^{-1}$ until 15 minutes before the conclusion of cardiopulmonary bypass. Cardiopulmonary bypass was performed with a closed system in 5 patients with and in 5 patients without the use of cardiotomy suction. Blood samples were obtained before and after cardiopulmonary bypass. D-dimers, fibrinopeptide A, prothrombin 1 and 2 fragments, thrombinantithrombin, and factor XIIa were determined.

Results: Values for factor XIIa remained almost unchanged in both groups, indicating a minor effect of contact activation. In patients without cardiotomy suction, post-cardiopulmonary bypass values for D-dimers, fibrinopeptide A, prothrombin 1 and 2 fragments, and thrombin-antithrombin were not significantly increased compared with pre-cardiopulmonary bypass values. In patients with cardiotomy suction, values obtained for these parameters had significantly increased compared with pre-cardiopulmonary bypass values and the values obtained in the group without cardiotomy suction after cardiopulmonary bypass.

Conclusions: With this protocol, hemostatic activation during cardiopulmonary bypass was almost completely attenuated when cardiotomy suction was avoided. Cardiotomy suction results in considerable activation of the coagulation system and should therefore be restricted and replaced by cell saving whenever possible.

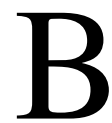
ivalirudin (Angiomax) is a direct thrombin inhibitor. The pharmacokinetics of bivalirudin are characterized by a short half-life of approximately 25 minutes and an elimination that is mainly achieved by proteolytic cleavage (80\%); the remaining $20 \%$ is cleared by renal excretion. ${ }^{1}$ This elimination mechanism, largely independent of particular organ functions, and its short half-life render bivalirudin an interesting alternative to or replacement for unfractionated heparin (UFH) for high-dose anticoagulation in percutaneous coronary intervention (PCI) and cardiovascular surgery. Bivalirudin has been shown to result in favorable outcomes as compared with UFH in large PCI trials, and it seemed promising during off-pump coronary artery bypass surgery when used at PCI dosage. ${ }^{2,3}$ In a recent pilot investigation involving 20 patients undergoing coronary artery bypass grafting (CABG), bivalirudin was successfully used for anticoagulation during cardiopulmonary bypass $(\mathrm{CPB}) .{ }^{4}$ The dosing scheme for that investigation was based on prior 
TABLE 1. Parameters of hemostatic activation before and after CPB

\begin{tabular}{|c|c|c|c|c|c|}
\hline Variable & $\begin{array}{l}\text { D-dimers } \\
(\mu \mathrm{g} / \mathrm{mL})\end{array}$ & $\begin{array}{c}\text { TAT } \\
(\mu \mathrm{g} / \mathrm{L})\end{array}$ & $\begin{array}{c}\text { FPA } \\
\text { (ng/mL) }\end{array}$ & $\begin{array}{l}\text { PTF1+2 } \\
\text { (nmol/L) }\end{array}$ & $\begin{array}{c}\text { FXIla } \\
\text { (ng/mL) }\end{array}$ \\
\hline \multicolumn{6}{|c|}{ Before CPB } \\
\hline CS & $0.4 \pm 0.3$ & $3.6 \pm 1.2$ & $5.1 \pm 2.1$ & $0.9 \pm 0.2$ & $1.4 \pm 0.6$ \\
\hline NCS & $1.1 \pm 1.0$ & $6.9 \pm 3.8$ & $6.6 \pm 3.7$ & $1.1 \pm 0.4$ & $0.8 \pm 0.2$ \\
\hline \multicolumn{6}{|c|}{ After CPB } \\
\hline CS & $3.9 \pm 3.7^{*}$ & $126 \pm 72^{*}$ & $130 \pm 65^{*}$ & $11.8 \pm 7.3^{*}$ & $1.2 \pm 0.2$ \\
\hline NCS & $1.1 \pm 0.9 \dagger$ & $7.6 \pm 4.2 \dagger$ & $16 \pm 10.2 \dagger$ & $1.1 \pm 0.4 \dagger$ & $1.0 \pm 0.1$ \\
\hline
\end{tabular}

$C P B$, Cardiopulmonary bypass; CS, group with cardiotomy suction; NCS, group without cardiotomy suction; TAT, thrombin-antithrombin complex; FPA, fibrinopeptide A; PTF1+2, prothrombin fragments 1 and 2; FXIIa, factor XIIa. *Significant difference compared with pre-CPB values. $†$ Significant difference compared with the CS group.

experiences with the direct thrombin inhibitor r-hirudin and large pools of pharmacokinetic data derived from PCI studies. $^{4,5}$

However, cardiac surgery involving CPB induces activation of the coagulation/inflammation system caused by contact of the blood with the large nonendothelial surfaces of $\mathrm{CPB}$, release and reinfusion of tissue factor-enriched blood from the operation field aspirated by cardiotomy suction (CS), surgical trauma, and reperfusion of ischemic tissue. These procoagulant effects have been shown to occur with the use of UFH as anticoagulation therapy and even with the use of coated extracorporeal circuits. ${ }^{6,7}$ The currently used bivalirudin scheme for anticoagulation during CPB has not yet been evaluated with regard to its effect on hemostatic activation caused by the same factors. This investigation was performed to evaluate whether the currently suggested protocol for anticoagulation with bivalirudin during CPB provides effective attenuation of hemostatic activation and to assess the influence of CS in this regard.

\section{Methods}

\section{Patients and Anticoagulation Protocol}

After approval by the local ethics committee and informed consent were obtained, 10 patients undergoing elective CABG without known disturbances of the hemostatic system or previous therapy with warfarin, aspirin, or clopidogrel for 5 days before surgery were enrolled in this prospective, randomized investigation. This pilot investigation was designed to assess a slightly different dosing protocol than the previous pilot study. ${ }^{4}$ The bolus for the pump was $50 \mathrm{mg}$ of bivalirudin, and the bolus for the patient was bivalirudin $1 \mathrm{mg} / \mathrm{kg}$ followed by a constant infusion of $2.5 \mathrm{mg}$. $\mathrm{kg}^{-1} \cdot \mathrm{h}^{-1}$ until 15 minutes before the conclusion of CPB. Patients were to receive an additional bolus of bivalirudin only if the ecarin clotting time decreased to less than 400 seconds. No change was allowed in the rate of continuous infusion. In all patients, normothermic CPB was performed with a closed non-heparin-coated CPB system with a collapsible venous reservoir and roller pumps. Patients were randomized into 2 groups of 5 patients each. In one group, CS was used in combination with a cell-saving device (anticoagulation with citrate), whereas in the other group, CS was clamped out, the heart was passively vented into the venous reservoir, and blood from the operation field was processed exclusively with a cell-saving device.

\section{Laboratory Analysis}

Blood samples for determination of bivalirudin concentrations and ecarin clotting time were obtained at 15-minute intervals. Blood samples for the determination of hemostatic activation were collected 10 minutes after administration of the bivalirudin bolus (immediately before the start of $\mathrm{CPB}$ ) and immediately after termination of $\mathrm{CPB}$. Concentrations of bivalirudin were measured as described previously. ${ }^{2} \mathrm{D}$-dimers, fibrinopeptide A, prothrombin fragments 1 and $2(\mathrm{PTF} 1+2)$, thrombin-antithrombin (TAT), and factor XIIa (FXIIa) were determined by standard commercially available enzyme-linked immunosorbent assay techniques.

\section{Statistical Analysis}

Statistical analysis was performed with analysis of variance by using the Duncan multiple-range test for post hoc analysis.

\section{Results}

There were 4 men and 1 woman with a mean age of $55.8 \pm$ 6.1 years in the CS group and 5 male patients with a mean age of $66.4 \pm 6.3$ years $(P=.03)$ in the group without CS. The mean duration of CPB was $114 \pm 12.6$ minutes in the CS group and $94.6 \pm 27.8$ minutes in the group without CS $(P=.18)$. Eighty-five data points were obtained for measurement of bivalirudin concentrations during CPB. Of these, 82 were above the target concentration of $10 \mu \mathrm{g} / \mathrm{mL}$ during $\mathrm{CPB}$. The mean bivalirudin concentrations during CPB were $13.0 \pm 2.5 \mu \mathrm{g} / \mathrm{mL}$ (range, $9.5-18.5 \mu \mathrm{g} / \mathrm{mL}$ ) in the CS group and $13.3 \pm 2.3 \mu \mathrm{g} / \mathrm{mL}$ (range, $8.0-17.4 \mu \mathrm{g} / \mathrm{mL}$ ) in the group without $\mathrm{CS}(P=.67)$. No patient required an additional bolus of bivalirudin.

The postoperative blood loss was $520 \pm 279 \mathrm{~mL}$ in the $\mathrm{CS}$ group and $500 \pm 281 \mathrm{~mL}$ in the group without CS $(P=$ .93). During the entire course in the hospital, in the CS group, 4 units of packed red blood cells (median, 0 ) and 4 units of fresh frozen plasma (median, 0) were transfused. In the group without CS, 12 units of packed red blood cells (median, 2), 5 units of fresh frozen plasma (median, 0), and 
1 unit of platelets were transfused. However, most transfusions in the group without CS were given to 1 patient, who underwent reoperation because of postoperative blood loss exceeding $1500 \mathrm{~mL}$; bleeding from a sternal artery was found to be the source of hemorrhage. All patients had an otherwise uneventful postoperative course and were discharged from the hospital on schedule.

Hemostatic activation data are presented in Table 1. Regarding the marker of the contact activation system, FXIIa, no significant changes were observed between preand post-CPB values in the 2 groups. The values for Ddimers, PTF1+2, fibrinopeptide A, and TAT as markers for thrombin and fibrin generation obtained after $\mathrm{CPB}$ revealed only a moderate increase in the patients in the group without $\mathrm{CS}$ as compared with pre-CPB values, whereas the values in the CS patients were significantly increased as compared with pre-CPB values and with the values obtained from the group without CS after CPB.

\section{Discussion}

This investigation was performed to assess the effect of the currently suggested on-pump dosage of bivalirudin on hemostatic activation during CPB. According to this protocol, bivalirudin concentrations were almost exclusively maintained above the minimal target concentration of $10 \mu \mathrm{g} / \mathrm{mL}$ during CPB. ${ }^{5}$ At these concentrations, contact activation by the nonendothelial surfaces of CPB was almost completely inhibited, as observed by FXIIa levels that were almost unchanged after $\mathrm{CPB}$ as compared with values obtained before CPB. Similar to anticoagulation during CPB with $\mathrm{UFH}$, the observed hemostatic activation seems to be predominately caused by activation of the tissue factor-related pathway. ${ }^{6}$ The fact that hemostatic activation was almost completely attenuated in the group without CS suggests that, analogous to UFH, the main source of this tissue factor-derived hemostatic activation is the blood aspirated from the operation field. ${ }^{7}$ When UFH is used, stagnant blood in the pericardium and pleural space remains anticoagulated, and thrombin generation is largely attenuated. Bivalirudin, a compound cleaved by thrombin itself, is a short-acting anticoagulant and ideally should be administered continuously in a "closed circulatory system" with homogenous distributed blood flow to maintain a consistent concentration and therapeutic effect. Stagnant blood, particularly in contact with tissue factor-enriched cavities (eg, pericardium and plural space), generates large amounts of thrombin, which may cause thrombus formation in the cavity or may activate the entire coagulation system if it is aspirated and reperfused into the circulation. This mechanism likely explains the observed marked effect of CS on systemic hemostatic activation during $\mathrm{CPB}$ compared with data with UFH. TAT was $3.0 \pm 0.6 \mathrm{nmol} / \mathrm{L}$ without $\mathrm{CS}$ versus $1.5 \pm 0.1 \mathrm{nmol} / \mathrm{L}$ with $\mathrm{CS}$. Published data from our institution using a closed system with CS demonstrated values for TAT of $25.2 \pm 21.0 \mu \mathrm{g} / \mathrm{L}$ versus $34.6 \pm 25.1$ $\mu \mathrm{g} / \mathrm{L}$, for D-dimers of $1.94 \pm 1.74 \mu \mathrm{g} / \mathrm{mL}$ versus $2.58 \pm$ $2.1 \mu \mathrm{g} / \mathrm{mL}$, and for PTF1+2 of $2.6 \pm 1.6 \mathrm{nmol} / \mathrm{mL}$, depending on variations of heparin management. ${ }^{8-10}$

Despite the marked thrombin generation in the group with CS, no thrombosis of the CPB circuit or thromboembolic complication of the patients was observed. The fact that bivalirudin concentrations were maintained at an equivalent level as compared with the group in which CS was strictly avoided suggests that the larger amounts of thrombin generated did not significantly decrease bivalirudin concentrations. Therefore, the observed hemostatic activation may not be associated with CPB thrombosis or thromboembolism, although larger studies are needed to test this assumption.

This investigation was limited by the small number of patients involved and the fact that only patients scheduled for $\mathrm{CABG}$ with a closed system were enrolled. However, even on the basis of this small set of data, our results provide convincing evidence that, with the current protocol for bivalirudin, hemostatic activation during CPB is effectively attenuated if CS is strictly avoided. The significant increases of selected parameters of hemostatic activation observed in the group with CS strongly suggest that aspiration of blood from the operation field should be avoided whenever possible and replaced by cell saving if bivalirudin is used for anticoagulation during CPB. This may limit indications for this agent if massive reinfusion of blood via the CS line and storage of large volumes in the cardiotomy reservoir are anticipated. However, it remains to be demonstrated how far this problem may be overcome by innovations in perfusion technique.

Further safety studies to assess the use of bivalirudin for anticoagulation during $\mathrm{CPB}$ are warranted. These studies have to particularly address the effect of CS on patient outcome. Accordingly, until these safety data have been compiled, particularly in view of the fact that the use of this agent for this indication is "off label," bivalirudin should be used cautiously for anticoagulation during CPB if extended use of CS during the procedure is necessary.

We are grateful to Anne Gale, ELS, of the Deutsches Herzzentrum Berlin for editorial assistance.

\section{References}

1. Bates SM, Weitz JI. The mechanism of action of direct thrombin inhibitors. J Invasive Cardiol. 2000;12:1F-12F.

2. Lincoff AM, Bittl JA, Harrington RA, Feit F, Kleimann NS, Jackmann $\mathrm{JD}$, et al. Bivalirudin and provisional glycoprotein IIb/IIIa blockade compared with heparin and planned glycoprotein IIb/IIIa blockade during percutaneous coronary intervention: REPLACE-2 randomized trial. JAMA. 2003;289:853-63.

3. Merry A, Raudviki PJ, Middelton NG, McDougall JM, Nand P, Miller $\mathrm{BP}$, et al. Bivalirudin versus heparin and protamine in off-pump coronary artery bypass surgery. Ann Thorac Surg. 2004;77:925-31. 
4. Koster A, Spiess B, Chew DP, Krabatsch T, Tambeur L, DeAnda A, et al. Effectiveness of bivalirudin as a replacement for heparin during cardiopulmonary bypass in patients undergoing coronary artery bypass surgery. Am J Cardiol. 2004;93:356-9.

5. Koster A, Chew D, Gruendel M, Bauer M, Kuppe H, Spiess BD. Bivalirudin monitored with the ecarin clotting time for anticoagulation during cardiopulmonary bypass. Anesth Analg. 2003;96:383-6.

6. De Somer F, Van Belleghem Y, Caes F, Francois K, Van Overbecke $\mathrm{H}$, Arnout J, et al. Tissue factor as the main activator of the coagulation system during cardiopulmonary bypass. J Thorac Cardiovasc Surg. 2002;123:951-8.

7. Weerwind PW, Lindhout T, Caberg NE, De Jong DS. Thrombin generation during cardiopulmonary bypass: the possible role of retransfusion of blood aspirated from the surgical field. Thromb J. 2003;1:3.
8. Aldea GS, Soltow LO, Cjhandler WL, Triggs CM, Vocelka CR, Crocket GI, et al. Limitation of thrombin generation, platelet activation, and inflammation by elimination of cardiotomy suction in patients undergoing coronary artery bypass grafting treated with heparin-bonded circuits. J Thorac Cardiovasc Surg. 2002;123: 742-55.

9. Koster A, Fischer T, Praus M, Haberzettl H, Kuebler WM, Hetzer R, et al. Hemostatic activation and inflammatory response during cardiopulmonary bypass: impact of heparin management. Anesthesiology. 2002;97:837-41.

10. Koster A, Chew D, Kuebler W, Habazettl H, Hetzer R, Kuppe H. High antithrombin III levels attenuate hemostatic activation and leucocyte activation during cardiopulmonary bypass. J Thorac Cardiovasc Surg. 2003;126:906-7.

Access to The Journal of Thoracic and Cardiovascular Surgery Online is reserved for print subscribers!

Full-text access to The Journal of Thoracic and Cardiovascular Surgery Online is available for all print subscribers. To activate your individual online subscription, please visit The Journal of Thoracic and Cardiovascular Surgery Online, point your browser to http://www.mosby.com/jtcvs, follow the prompts to activate your online access, and follow the instructions. To activate your account, you will need your subscriber account number, which you can find on your mailing label (note: the number of digits in your subscriber account number varies from 6 to 10). See the example below in which the subscriber account number has been circled:

\section{Sample mailing label}

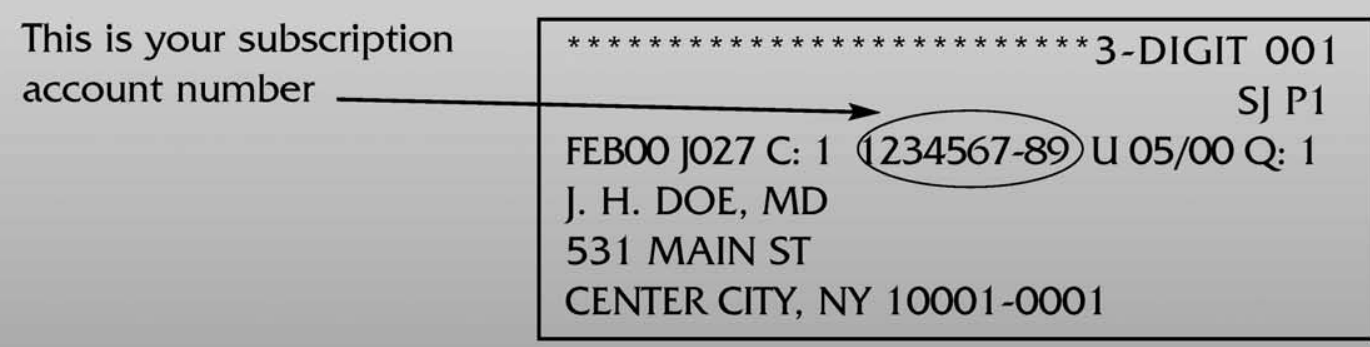

Personal subscriptions to The Journal of Thoracic and Cardiovascular Surgery Online are for individual use only and may not be transferred. Use of The Journal of Thoracic and Cardiovascular Surgery Online is subject to agreement to the terms and conditions as indicated online. 